\title{
A CASE REPORT ON UTERINE AV MALFORMATION IN LOWER UTERINE SEGMENT PLACENTAL IMPLANTATION
}

Hima Bindu ${ }^{1}$, Ruksana ${ }^{2}$, Syamala ${ }^{3}$, Usharani ${ }^{4}$

\section{HOW TO CITE THIS ARTICLE:}

Hima Bindu, Ruksana, Syamala, Usharani. "A Case Report on Uterine AV Malformation in Lower Uterine Segment Placental Implantation". Journal of Evolution of Medical and Dental Sciences 2014; Vol. 3, Issue 06, February 10; Page: 1512-1517, DOI: 10.14260/jemds/2014/2017

ABSTRACT: Uterine Arterio-venous malformations (AVM) are rare and potentially life threatening condition. AV malformations may be congenital or acquired. We report a case of acquired uterine AV malformation at the placental implantation site in the lower uterine segment which complicated the diagnosis.

KEYWORDS: Uterine AV malformation, uterine artery embolization, placental neoplasia.

INTRODUCTION: Arterio venous malformations of the uterus are uncommon entities and should be considered in patients who present with unexplained profuse genital bleeding. This entity is generally associated with presence of molar disease, choriocarcinoma and uterine surgery, but may also be congenital1-3. We report a case of acquired uterine AV malformation at the placental implantation site in the lower uterine segment who presented to us with recurrent episodes of bleeding after $2^{\text {nd }}$ trimester abortion.

CASE REPORT: A 28 year old female, P1L1A1 came to us with recurrent episodes of bleeding per vagina for past 2 months after spontaneous expulsion of fetus at 15weeks of gestation on 13/5/13 at a at a private clinic.

Her last child birth was 6 yrs. ago, delivered by caesarian section. She had H/O Dilatation \& curettage done for menorrhagia 2yrs back.

She conceived spontaneously Two years later and was diagnosed to have an intrauterine gestational sac implanted in the lower uterine segment. She had a spontaneous complete abortion at 16 weeks with a massive postabortal vaginal bleeding. D\&C was done under anesthesia because of excessive vaginal bleeding and blood transfusion was given .Tissue was not sent for histopathological examination after D\&C.

She had persistent complaints of vaginal bleeding on and off for which conservative management was given. Two months later she attended a private hospital due to persistent vaginal bleeding and B-hcg level $52.27 \mathrm{mIU} / \mathrm{ml}$ on 17/7/13. Ultrasonography and Color Doppler was done on 16/7/13 (Fig. 1) which shows a picture of highly vascular mass $7 \times 5 \mathrm{~cm}$ in cervical region. MRI pelvis 17/7/13 (Fig. 2) showed large ill-defined heterogeneous mass 86.2x65.7 mm size with prominent vessels in lower segment and cervix suggestive of Large uterine AV malformation .MR Angiography showed multiple vessels within the mass .Screening Doppler studies showed cluster of vessels with feeding arteries and draining veins and the patient was referred to our hospital. 


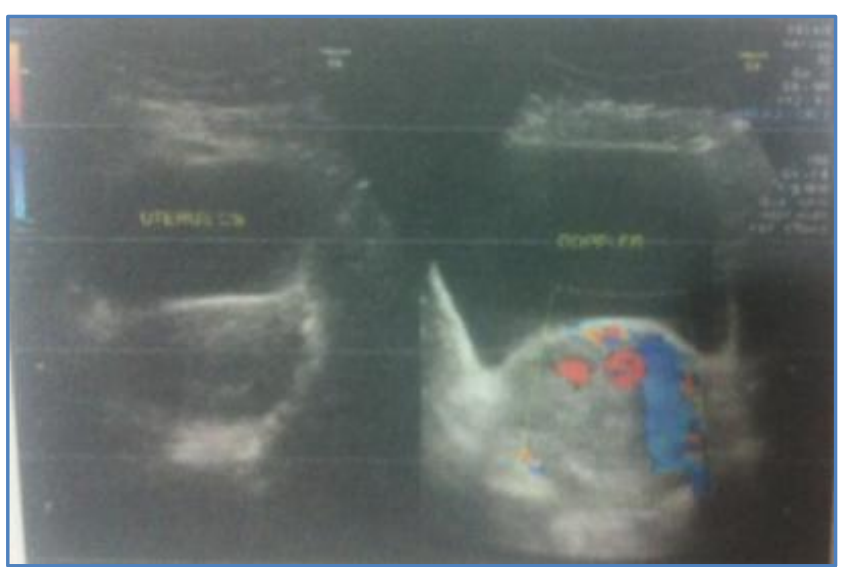

Fig. 1: Ultrasonography and Color Doppler on suggestive of highly vascular mass $7 \times 5 \mathrm{~cm}$ in cervical region

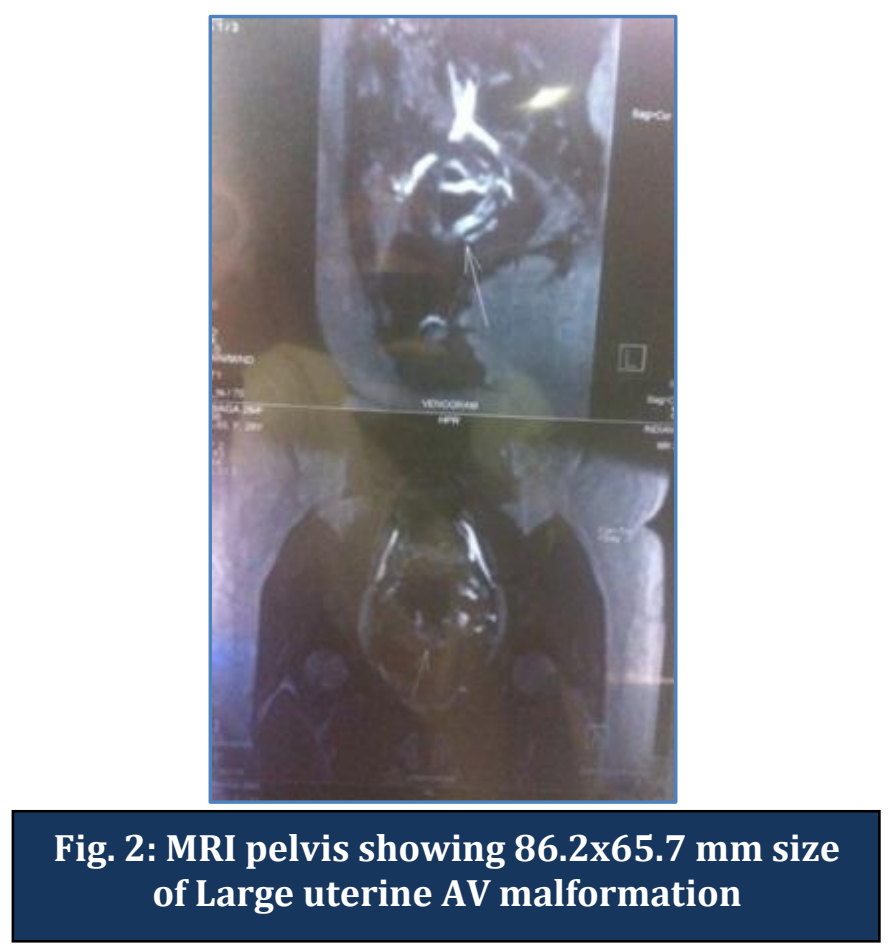

At the time of admission (29/7/13) in our hospital vitals were stable, no vaginal bleeding, and mild pallor was present. On per vaginal examination external os was closed. Uterus was bulky, cervix was ballooned out and bilateral fornices were free. Her Hemoglobin was 9.4 gm. \%, BT, CT and PTT were normal. Urine for pregnancy test was negative. B-Hcg level was $10.5 \mathrm{mIU} / \mathrm{ml}$ on 29/7/13.

Examination under anesthesia and biopsy was planned to rule out placental site trophoblastic tumor. Uterine artery embolization was also planned if needed. During examination under anesthesia with ultrasound guidance the mass was identified, curettage for endometrium was done, and minimal quantity of foul smelling tissue obtained which was sent for histopathological examination. Intracervical digital examination induced profuse bleeding from the intracervical mass which was felt firm and was 4-5 cm in diameter. Bakri balloon was instilled in the intracervical canal with $70 \mathrm{cc}$ 
normal saline which arrested the bleeding and uterine artery embolization was done. She received two units of blood transfusion. Histopathological report came out as products of conception. Postoperative period was uneventful. Patient started on OCP`s and discharged.

Repeat ultrasonography done

1) Two weeks later on 13/8/13 TVS Pelvis (Fig 3) - uterus enlarged in size with irregular echogenic focus in the cervical canal? Post embolization picture. Mass seen in the cervical canal 5.6 x $5.9 \mathrm{~cm}$. Minimal vascularity seen in the periphery of mass and repeat B-hcg $<2 \mathrm{miu} / \mathrm{ml}$.

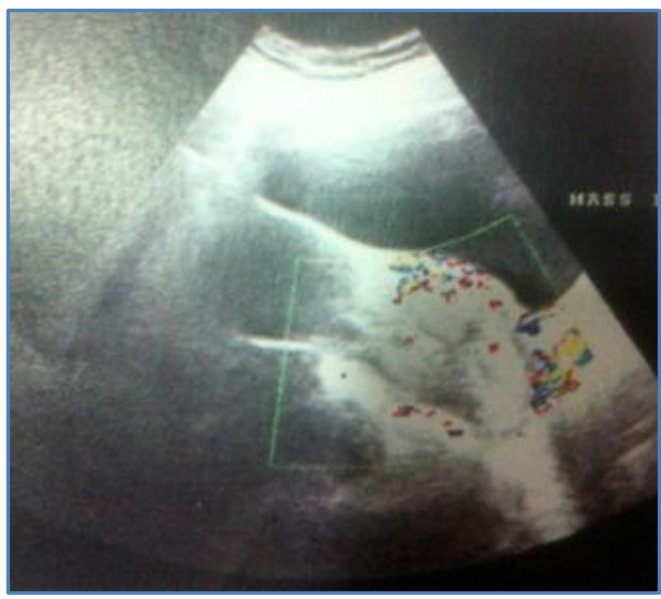

Fig. 3: TVS Pelvis - No products of conception. Mass seen in the cervical canal with minimal vascularity

2) Two months following uterine artery embolization, 17/9/13 TVS Pelvis (Fig 4) showed normal appearing uterus with mass near the cervix measuring $2.3 \times 2.9 \mathrm{cms}$, no vascularity on color Doppler. Patient was on oral contraceptive pills and was having regular withdrawal bleeding.

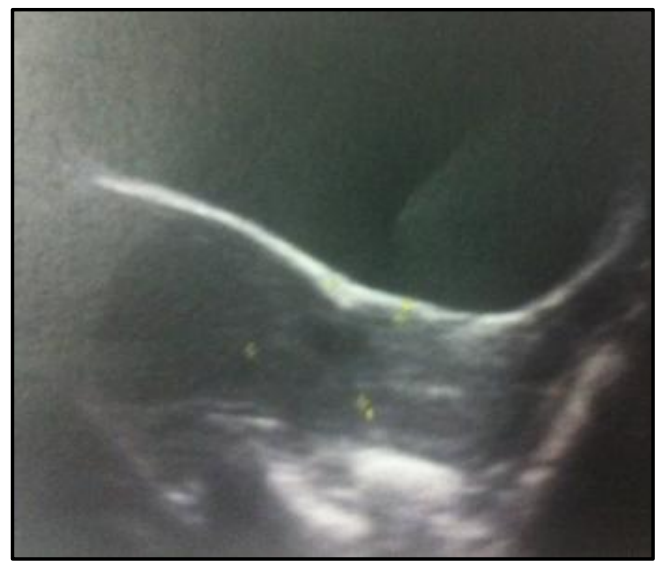

Fig. 4: TVS Pelvis - compared to previous scan mass has regressed 
3) Two months later the previous scan, on 15/11/13, TVS pelvis (Fig 5) showed complete regression of mass with normal appearing uterus, cervix, and ovaries. Patient was advised to stop oral contraceptive pills.

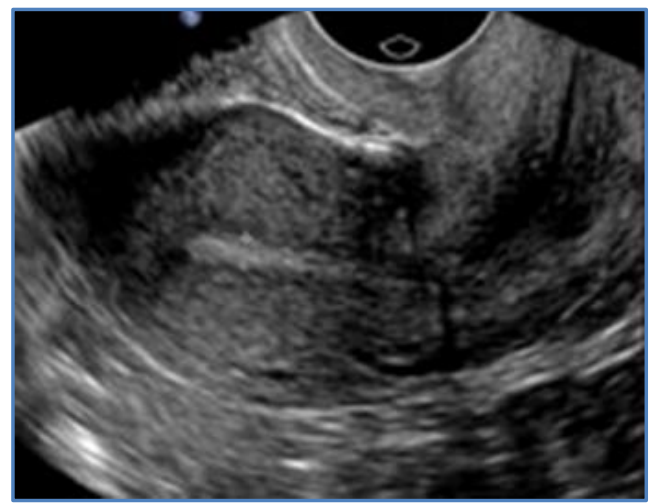

Fig. 5: TVS pelvis - complete regression of mass with normal uterus and cervix

\section{DISCUSSION:}

Incidence: Dubreuil and Loubat reported the first case of uterine AVM in 19261.

To date, there are fewer than 100 cases reported in the literature ${ }^{2}$.

Etiology: Uterine AVM may be congenital or acquired ${ }^{3-5}$.

Acquired AVM are more common and usually follows a history of previous uterine trauma, such as curettage procedures, caesarean section, or pelvic surgery. The potential to develop abnormal communication between arteries and veins occurs during the healing process, typically when a single artery joins a single vein. Acquired AVM is also associated with infection, retained POC, gestational trophoblastic disease, gynecologic malignancies, and exposure to diethylstilbestrol

Diagnosis: Acquired uterine Arterio-venous malformation is a rare but potentially life threatening condition and as such must be considered in the differential diagnosis of cases of abruption, profuse vaginal bleeding following uterine curettage. The condition can easily be confused with retained products of conception and gestational trophoblastic disease. ${ }^{6}$

Uterine AVMs result in sudden and massive vaginal bleeding that maybe life-threatening. They may occur as late postpartum hemorrhage or post abortion hemorrhage, and the bleeding results from a spontaneous vessel rupture or vessel rupture triggered by a D\&C.

Angiography remains the gold standard imaging technique for diagnosis of uterine $\mathrm{AVM}^{7}$

Management: Uterine artery embolization is effective in controlling hemorrhage. ${ }^{8}$

Management includes measures to stabilize the patient, uterine tamponade with Foley's catheter or rolled gauze packing, and medical therapies like estrogens, progestins, methylergonovine, danazol, and 15-methyl-prostaglandin F2alpha. In our case we used Bakri balloon instilled with 70 cc normal saline initially when profuse bleeding started. 
In stable women, expectant management, surgical removal of an AVM, laparoscopic bipolar coagulation of the uterine blood vessels, and long-term medical therapy with combined oral contraceptive pills are reported 9 .

Recent reports have described successful treatment of uterine artery embolization with different materials used singly or in combination such as autologous blood clot, gel foam, microfibrillar collagen, polyvinyl alcohol, isobutyl cyanoacrylate and steel coil spring occluders. ${ }^{4}$

Gonadotropin-releasing hormone agonists have been used as an adjunct to embolization and 6 months of therapy reduced the size of a uterine AVM from $5.1 \times 3.8 \mathrm{~cm}$ to $1.4 \times 1.0 \mathrm{~cm} .{ }^{10}$

Prabhu et al also reported a case of uterine AVM treated with spring coil, who resumed normal menstruation with the procedure. ${ }^{11}$

These case report studies shows that patient presenting with recurrent bleeding after D\&C, One should have high index of suspicion of AV malformations and should be confirmed by color Doppler study prior to repeat D\&C. The usual diagnosis in such type of patients with recurrent bleeding is either incomplete abortion or gestational trophoblastic disease. B-Hcg levels will exclude the diagnosis of Gestational Trophoblastic Disease.

CONCLUSION: Uterine Arterio-venous malformations are rare lesions with a considerable risk potential. Recurrent or massive life-threatening vaginal bleeding may occur. D \& C procedure may further worsen the situation if the condition is not diagnosed. High index of Clinical suspicion is essential for a prompt diagnosis and treatment.

\section{REFERENCES:}

1. Dubreuil G, Loubat E. Aneurysme crisoide de l'uterus. Ann Anat Pathol. 1926; 3:697-718.

2. Hickey M, Fraser I. Clinical Implications of Disturbances of Uterine Vascular Morphology and Function. Baillieres Clin Obstet Gynaecol. 2000; 14(6):937-951. [PubMed

3. Polat P, Suma S, Kantarcy M, Alper F, Levent A. Colour Doppler Ultrasound in the Evaluation of Uterine Vascular Abnormalities. Radiographics. 2002; 22:47-53. [PubMed]

4. Fleming H, Ostor A, Pickel H, Fortune D. Arteriovenous Malformations of the Uterus. Obstet Gynaecol. 1989; 73(2):209-213. [PubMed]

5. Grivell R, Reid K, Mellor A. Uterine Arteriovenous Malformations: A review of the Current Literature. Obstet Gynaecol Survey. 2005; 60(11):761-767. [PubMed]

6. Halperin R, Schneider D, Maymon R, Peer A, Pansky M, Herman A. Arteriovenous malformation after uterine curettage: a report of 3 cases. J Reprod Med. 2007 May; 52(5):445-9.

7. Bottomoley JP, Whitehouse GH. Congenital arteriovenous malformation of the uterus demonstrated by angiography. Acta Radiological Diagnostica1975; 16:43-48.

8. Nicholson AA, Turnbull LW, Coady AM, Guthrie K. Diagnosis and management of utrine arteriovenous malformations. Clin Radiol1999; 54(4)265-9.

9. Bagga R, Verma P, Agarwal N, Suri V, Bapuraj JR. Failed angiographic embolization in uterine arterio venous malformation: a case report and review of literature. Available at www.medscape.com/viewarticle/567523_print Accessed on 29/7/2008.

10. Morikawa M, Yamada T, Yamada H, Minakami H. Effect of gonadotropin-releasing hormone agonist on a uterine arteriovenous malformation. Obstet Gynecol. 2006; 108:751-753. 


\section{CASE REPORT}

11. Prabhu A, Gupta A, Parulekar S. Uterine Arteriovenous Malformation A rare case of Uterine Haemorrhage.

\section{AUTHORS:}

1. Hima Bindu

2. Ruksana

3. Syamala

4. Usharani

\section{PARTICULARS OF CONTRIBUTORS:}

1. Final Year Post Graduate, Department of Obstetrics and Gynaecology, Sri Ramachandra Medical Center, Porur, Chennai.

2. Assistant Professor, Department of Obstetrics and Gynaecology, Sri Ramachandra Medical Center, Porur, Chennai.

3. Associate Professor, Department of Obstetrics and Gynaecology, Sri Ramachandra Medical Center, Porur, Chennai.
4. Professor, Department of Obstetrics and Gynaecology, Sri Ramachandra Medical Center, Porur, Chennai.

\section{NAME ADDRESS EMAIL ID OF THE} CORRESPONDING AUTHOR:

Dr. Hima Bindu M, E 307 - Jamine Courte,

Eta Star Apartments,

Kaattupaakam, Chennai - 600056.

E-mail: himabindumasina@gmail.com

Date of Submission: 15/01/2014.

Date of Peer Review: 16/01/2014.

Date of Acceptance: 29/01/2014.

Date of Publishing: 08/02/2014. 